\title{
ULTRAWEAK LUMINESCENCE OF THE CHARACEAE PLANTS UNDER THE CIRCUMSTANCES OF CYCLICAL CHANGES IN TEMPERATURE
}

\author{
ROBERT BORC ${ }^{A}$, ANDRZEJ DUDZIAK ${ }^{\mathrm{A}}$, ANNA JAŚKOWSKA ${ }^{\mathrm{B}}$ \\ ${ }^{\text {A }}$ Department of Applied Physics, Lublin University of Technology, Nadbystrzycka 38, 20-618 Lublin, Poland; \\ ${ }^{B}$ Institute of Environmental Protection Engineering, Lublin University of Technology, Nadbystrzycka 40B, 20-618 Lublin, Poland
}

Received February 11, 2011; accepted July 04, 2011; published online July 9, 2011

\begin{abstract}
The study sought to measure ultraweak chemiluminescence (UWL) of Nitellopsis Obtusa plants with regards to temperature changes within the range from $4^{\circ} \mathrm{C}$ to $38^{\circ} \mathrm{C}$. The temperature changes were being executed in reversible cycles. The variations of UWL intensity with temperature had an exponential character. In case when temperature was changed rapidly by $5^{\circ} \mathrm{C}$ every 20 min or fluently with rate of $0.17^{\circ} \mathrm{C} / \mathrm{min}$ we observed a temperature hysteresis loop in the first cycles and the loop character disappeared in the second cycles. When the temperature was being changed fluently but faster $\left(1.3^{\circ} \mathrm{C} / \mathrm{min}\right)$ after 3 cycles (about 2 hours) the curves no longer manifested the loop character. This phenomenon can point that the plants adapted themselves to the temperature changes. We also observed a stimulation of UWL made in successful cycles. Our spectral experiments showed that the UWL may consist mainly of emission of the singlet oxygen sigma $(762 \mathrm{~nm})$ and induced emission of chlorophyll.
\end{abstract}

\section{INTRODUCTION}

In living organisms, both in animals and in plants, a continuous luminescence takes place with very little amount of the visible and infrared light quanta called ultraweak luminescence (UWL) (Devaraj, Usa \& Inaba, 1997) The UWL sources of biological objects are the excited atoms and particles, which are components of the cells of those objects. Those excitations are connected with some biochemical reactions occurring within the cell. The intensity of the luminescence of the plants with not perturbed homeostasis is, as a rule, stationary and very weak, mainly $10-10^{4}$ photons $\cdot \mathrm{s}^{-1} \cdot \mathrm{cm}^{-2}$, which lies far below the energetic threshold of the human eye. The homeostasis perturbations connected both with physical and chemical factors interacting on the cell trigger a respective reaction, e.g. changes of UWL.

One of the aforementioned factors are temperature changes. The temperature increase in plants causes the UWL increase satisfying in an approximate way the Arrhenius equation (Roschger, Scott, Devaraj \& Inaba, 1993). The correlation occurs in the temperature range where no considerable disturbances in the function of the metabolic apparatus are observed.

The measurements of UWL dependent on temperature are well known for cultivated plants (Slawinski \& Popp, 1987; Roschger et al., 1993; Triglia, Grasso, Musumeci, Scordino, Luciani, Battiato, Allegra \& Rajfur, 1993; Makino, Kato, Iyozumi \& Aoshima, 2005). Results of this type of studies on algae living in water medium are unknown (the authors have failed to find any), although temperature investigations of membrane changes as well as growth and transport processes in Chara are still intensively continued because algae are the sort of plants that is very sensitive to temperature changes (Radenovic, Maksimov, Jeremic \& Vuchinich, 2000; Ogata, 2000; Djurisić \& Andjus, 2000; Proseus, Zhu \& Boyer, 2000; Demidchik, Naidun, Yablontskaya, Sokolik \& Yurin, 2001; Hertel \& Steudle, 1997; Beljanski, Andjus, HadziPavlović, Srejic \& Vucelić, 1997).

The study of UWL intensity in the function of cyclic temperature changes enables us to determine the degree of the immunity of a cell or the whole organism to the range and rate of temperature change. The area between the curves, which are the result of carrying out full cycles (a temperature hysteresis loop) can determine the state of a homeostasis violation of the organism under research (Slawinski \& Popp, 1987).

In recent years there have been a lot of studies of ultraweak luminescence from human body including also the influence of temperature on photon emission (Nakamura \& Hiramatsu, 2005; Kobayashi, Kibuchi \& Okamura, 2009).

We studied the susceptibility to the temperature change in the Characeae plants. They are model systems in the electrophysiological studies, and the measurements of electrical parameters of cell membrane in various temperatures have already been made in their case. The 
parameters in question are function of the state of cellular metabolism (Paszewski \& Śpiewla, 1986; Blatt, 1974). Therefore it was interesting to find out how temperature changes in these plants affect the UWL intensity, which in turn also reflects any disturbances in organism homeostasis. Moreover, these cells can live very well in darkness, which is important during the luminescence researches. No essential changes in the cytoplasm movement were observed even after several weeks under these conditions (Gabryś, 1979). The Characeae plants in natural environment grow a few meters under the water surface. The range of temperature changes during the year in this water environment is significant (for diurnal cycles it is much smaller) but the velocity of these changes is very low. However, in case of human interference, for instance when a lake is supplied with hot water discharged from power station, the water temperature variations may be much bigger and faster. Especially, the following questions inclined us to undertake the studies: 1) in what way does the rate of the temperature changes within the given range influence the disturbances of the ultraweak luminescence level? 2) does the adaptation process exist and if so within how much time does it begin? 3) do the processes accountable for UWL change together with temperature changes?

\section{MATERIALS AND METHODS}

The Nitellopsis Obtusa (Desv. in Lois) plants used in the experiments were taken from Lake Zagłębocze, near Lublin in Poland, from the depth of $2 \mathrm{~m}$. They were cultured in the laboratory in the air-conditioned natural pond water under a natural day/night regime at room temperature $\left(18-20^{\circ} \mathrm{C}\right)$. The water was carried every time together with the plants from the lake $(\mathrm{pH}$ about 7.8; ion composition in mmol/L: $\mathrm{Na}^{+}-0.23, \mathrm{~K}^{+}-0.70$, $\left.\mathrm{Cl}^{-}-0.19, \mathrm{Ca}^{2+}-0.84, \mathrm{Mg}^{2+}-0.01\right)$. This was supposed to keep the most natural environment regime. Our experiments showed that the plants condition was the best then and cultivation could be kept the longest.

Because in the electrophysiological measurements the internodal cells were investigated, therefore cells of the same kind were used in ultraweak luminescence studies. Out of the whole population only single internodal cells were selected. This procedure was undertaken so as not to cut the remaining part of the plant, because cut endings, as damaged, are a source of additional emission. This phenomenon was observed in our investigations by means of the Molecular Light Imager (Jaśkowska, Górski \& Dudziak, 2003). Selected plants were gently but thoroughly washed by running water. Then they were kept for about $1 / 2$ hour in a solution containing 10 $\mu \mathrm{g} / \mathrm{cm}^{3}$ streptomycin and $20 \mu \mathrm{g} / \mathrm{cm}^{3}$ penicillin $\mathrm{G}$ to avoid artefacts due to bacteria likely to be living on the surface of the Characeae cells (Krauss, 1962).
Before UWL measurements, all samples were kept overnight in complete darkness for about $15 \mathrm{~h}$ in order to avoid artefacts due to long-lasting luminescence (Jaśkowska, Borc, Dudziak, Milczarek \& Śpiewla, 2001; Yan, Popp, Sigrist, Schlesinger, Dolf, Yan, Cohen \& Chotia, 2005). These plants were kept in artificial pond

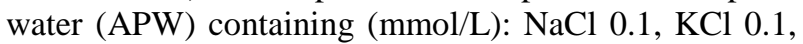
$\mathrm{CaCl}_{2} 0.1$ and $20 \mathrm{mmol} / \mathrm{L}$ Hepes buffer. To achieve $\mathrm{pH}$ $7.5-7.8,10 \% \mathrm{NaOH}$ was used. Such ion composition is similar to natural water from the lake, whereas APW made of the redistilled water is sterile and devoid of possible microorganisms. The solution of such composition is the standard medium used in investigations with the same as our plant organisms (Wayne, Staves, \& Leopold, 1990; Uchida, Nemoto \& Tsuchiya, 1995; Korthout, Berecki, Bryin, van Duijn \& Wang, 2000).

Light emission was detected within the range 350 $850 \mathrm{~nm}$ with a high-sensitivity photon-counting system, utilising a low noise 9558 A photomultiplier tube (PMT) with photocathode S-20 (THORN EMI, UK). PMT was cooled down to $265 \mathrm{~K}$. The impulses from the photomultiplier were shaped by amplifier and then counted and registered by a computer. The system serves as an automatic filter spectrometer with a set of glass filters (long pass filter) SCHOTT type DIN 58191, the socalled cut-off filters enabling the measurement of the UWL spectral distribution (Inaba, 1988; Tryka, 1998). With the increasing wavelength the quantum efficiency of photocathode decreases and the filter transmittance curves deteriorate. Therefore the histograms of the UWL spectral distribution with acceptable errors are plotted only to the wavelength of $715 \mathrm{~nm}$ (Fig.4). The obtained standard uncertainty of an individual measurement was $18 \mathrm{imp} / 20 \mathrm{~s}$ at luminescence level of $200 \mathrm{imp} / 20 \mathrm{~s}$ and 30 $\mathrm{imp} / 20 \mathrm{~s}$ at luminescence level of $900 \mathrm{imp} / 20 \mathrm{~s}$. The significance of the observed differences was calculated by means of test $t$. The changes of the luminescence background, i.e. emission from the light-proof chamber with APW only, caused by heating or cooling was about $1.2 \mathrm{imp} \cdot \mathrm{K}^{-1}$ for one minute measurements.

The sample (30 internodal cells in $20 \mathrm{ml}$ APW) under examination was placed in a measure chamber, whose temperature was regulated by means of the Peltier plates. The probe for the temperature measurement was immersed directly in the plant environment. Temperature changes (increase followed by decrease) were carried out with an established rate until a several cycles for each plant probe were executed. The state of plants' functioning after the experiment was checked by studying the turgor and cytoplasmic streaming. These factors were treated as a basic criterion of functional state. >From our observations it appears that the survival ratio equals $100 \%$, i.e. all the cells showed turgor after the experiment. The velocity of cytoplasmic streaming, which changes together with temperature (Uchida et al., 1995), also returned to the level recorded before the start 
of experiment $(50-60 \mu \mathrm{m} / \mathrm{s}$ at room temperature).

\section{RESULTS AND DISCUSSION}

In order to achieve the set objectives the UWL measurements were carried out for rapid as well as for fluent temperature changes, the last of which were made with different speed. The dependence of the number of impulses (after subtraction of the background) on the temperature of the Nitellopsis Obtusa cells is presented in figures 1, 2 and 3 (all curves are representative and chosen from three independent measurement series).

At Fig. 1 the temperature was changed from $4^{\circ} \mathrm{C}$ to $38^{\circ} \mathrm{C}$ and again to $4^{\circ} \mathrm{C}$, thus forming one full cycle. The average rate of fluent temperature change was $0.17^{\circ} \mathrm{C} / \mathrm{min}$ (the time of the whole cycle is equal to 7 hours). In the range of temperature $13^{\circ} \mathrm{C}-28^{\circ} \mathrm{C}$ the UWL rising curve is below the falling one (the differences are significant at the level of 0.01). In this way, we observe the courses of the loop type (a temperature hysteresis of UWL). After we had finished the first cycle, the measurements were then continued with an increase of temperature up to $30^{\circ} \mathrm{C}$. These data appeared to overlap with the falling curve in the first cycle. The beginning of the second cycle is not shown for the sake of clarity of the figure.

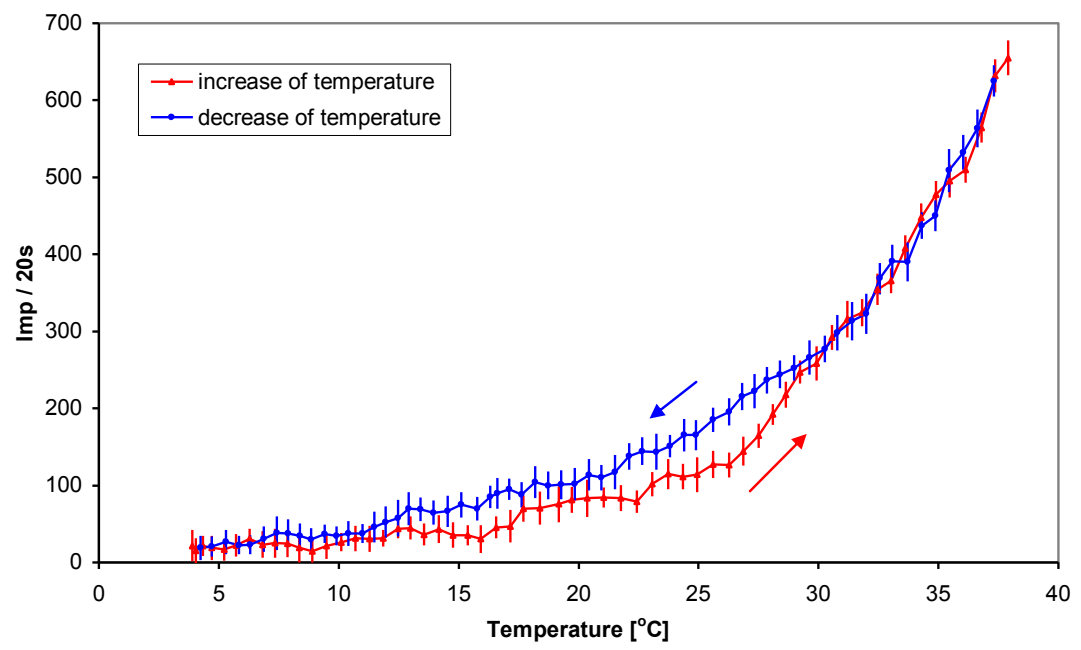

Fig. 1. Variations of UWL from Characeae cells for one cycle of continuous slow temperature changes $4^{\circ} \mathrm{C}-38^{\circ} \mathrm{C}-4^{\circ} \mathrm{C}$ (the mean rate was $0.17^{\circ} \mathrm{C} / \mathrm{min}$ ). Each point represents the mean value of eight readout, vertical bars are the standard deviations.

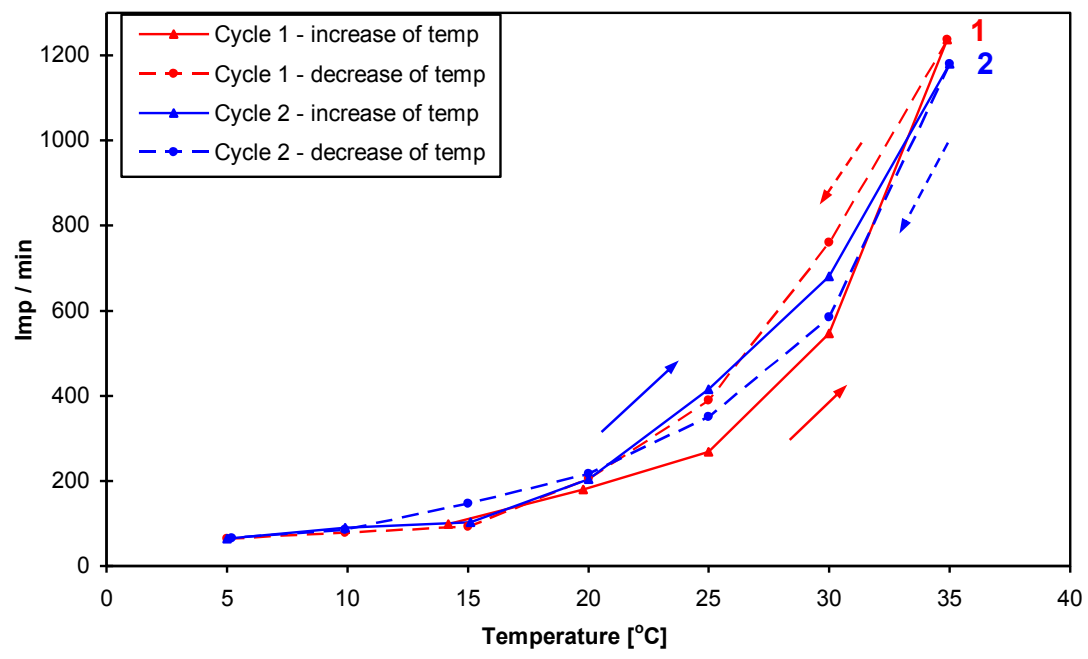

Fig. 2. Variations of UWL from Characeae cells for two consecutive cycles of step temperature changes of $5^{\circ} \mathrm{C}$ every 20 minutes. First cycle: $15^{\circ} \mathrm{C}-35^{\circ} \mathrm{C}-5^{\circ} \mathrm{C}$; second cycle: $5^{\circ} \mathrm{C}-35^{\circ} \mathrm{C}-5^{\circ} \mathrm{C}$. Each point represents the mean value of ten readout. The standard error (from low to high temperature) is from 9 to $15 \mathrm{imp} / \mathrm{min}$, respectively. 
In the next series of measurements (Fig.2), the temperature was changed rapidly by $5^{\circ} \mathrm{C}$ every $20 \mathrm{~min}$. The first cycle was $15^{\circ} \mathrm{C}-35^{\circ} \mathrm{C}-5^{\circ} \mathrm{C}$ and the second $5^{\circ} \mathrm{C}-35^{\circ} \mathrm{C}-5^{\circ} \mathrm{C}$. The full cycle lasted four hours. The temperature hysteresis loop is observed in the first cycle. The differences between the rising curves and the falling ones at the temperature of $25^{\circ} \mathrm{C}$ and $30^{\circ} \mathrm{C}$ are important at the significance level of 0.01 . In the second cycle the hysteresis loop character disappeared.

The measurements of UWL were also carried out for a similar temperature range but the temperature was being changed faster and in a continuous way - during 4.5 hours in 6 cycles. The first four cycles are presented in Fig.3. The rate of the fluent changes was $1.3{ }^{\circ} \mathrm{C} / \mathrm{min}$ (one cycle lasted $45 \mathrm{~min}$ ), which was essentially faster than the same changes in Fig.1. In the second and third cycles there appear temperature hysteresis loops (the rising curves are below the falling ones and the differences, when the loops are wide, are significant at the level of 0.01). Generally, those alterations are accompanied by the UWL increase. In the next fourth cycle, the loop was not obtained and the luminescence intensity clearly diminished. The fifth and sixth cycles, which were not shown in Fig.3, are in their shape and course similar to the fourth one. Similarities of those courses show the phenomena of exhaustion i.e. Characeae plants adaptation to given temperature changes of the environment. If we assume that the full adaptation occurred in the second part of the third cycle - i.e. when it begins to overlap with the fourth cycle (about $22^{\circ} \mathrm{C}$ ) - then the time to accomplish the adaptation (counted from the beginning of measurement) is equal to about 2 hours. Such a recurring course in the fourth cycle can be described by exponential function with $\mathrm{R}^{2}=0.90$ for which a Van't Hoff coefficient $\mathrm{Q}_{10}$ is relatively high and equals 3.3. This value is in the upper value range of $\mathrm{Q}_{10}$ for biological processes, but it is worth noting that it is obtained for plants previously undergoing intense stimulation by relatively rapid cyclical changes in temperature.

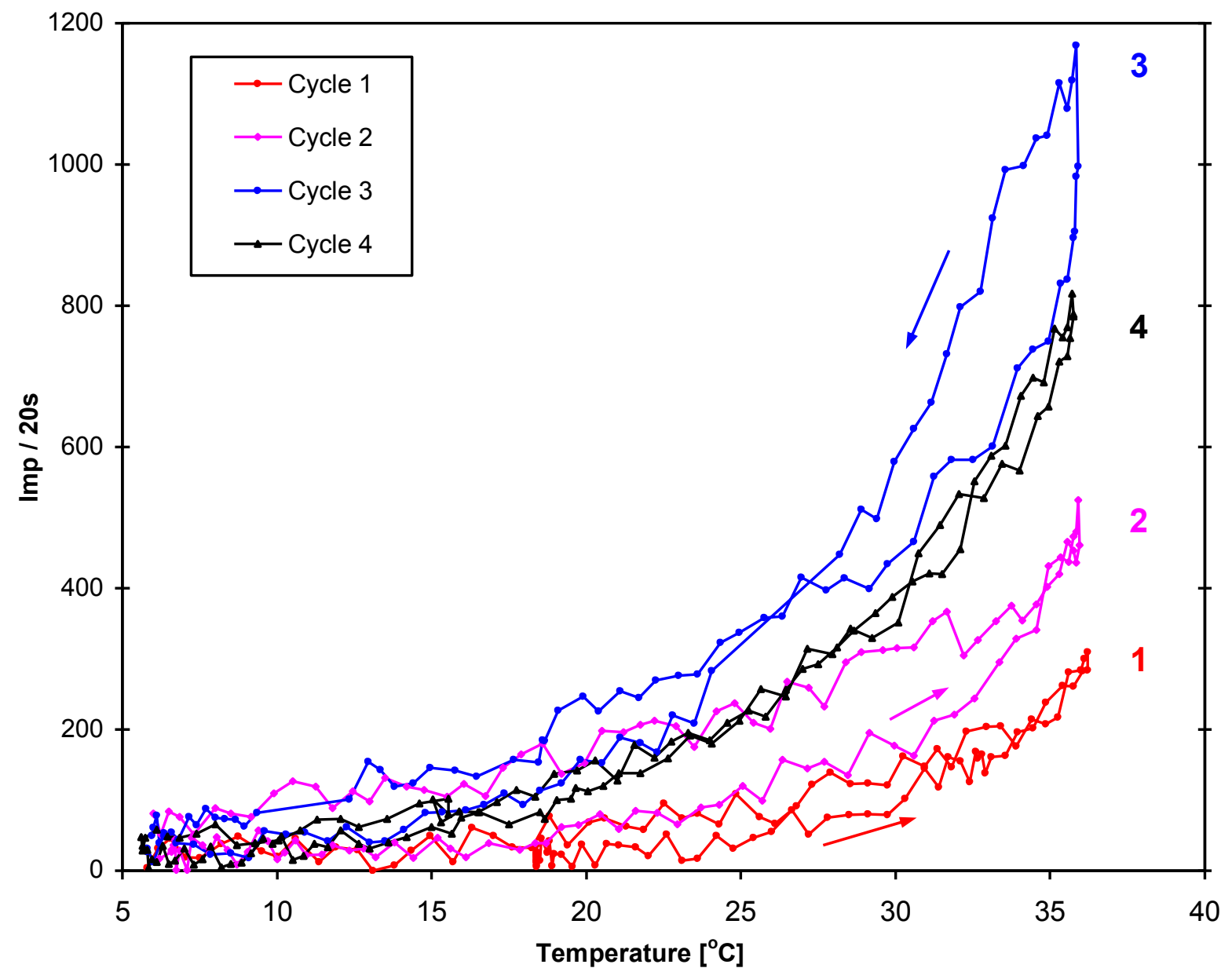

Fig. 3. Variations of UWL from Characeae cells for four consecutive cycles of continuous temperature changes (the mean rate $1.3^{\circ} \mathrm{C} / \mathrm{min}$ ). First cycle: $18^{\circ} \mathrm{C}-36^{\circ} \mathrm{C}-6^{\circ} \mathrm{C}$; next cycles: $6^{\circ} \mathrm{C}-36^{\circ} \mathrm{C}-6^{\circ} \mathrm{C}$. 
The spectral UWL measurements were carried out in order to answer the following questions: what kind of processes are accountable for ultraweak emission of the plants under study and whether they change with temperature. For that purpose, we used the system of 20 cut-off filters, by means of which the spectral analysis within the wave range of $350-850 \mathrm{~nm}$ was performed. The spectral distribution of ultraweak luminescence measured at the temperature of $20^{\circ} \mathrm{C}$ is presented at Fig.4. For the higher temperatures i.e. 25, 30 as well as $35^{\circ} \mathrm{C}$ we studied the changes of the ratio of the intensity of electromagnetic radiation in the visible range to the infrared radiation. It turned out that over $70 \%$ of emission occurred within the range of $715-850 \mathrm{~nm}$, and it did not depend on temperature.

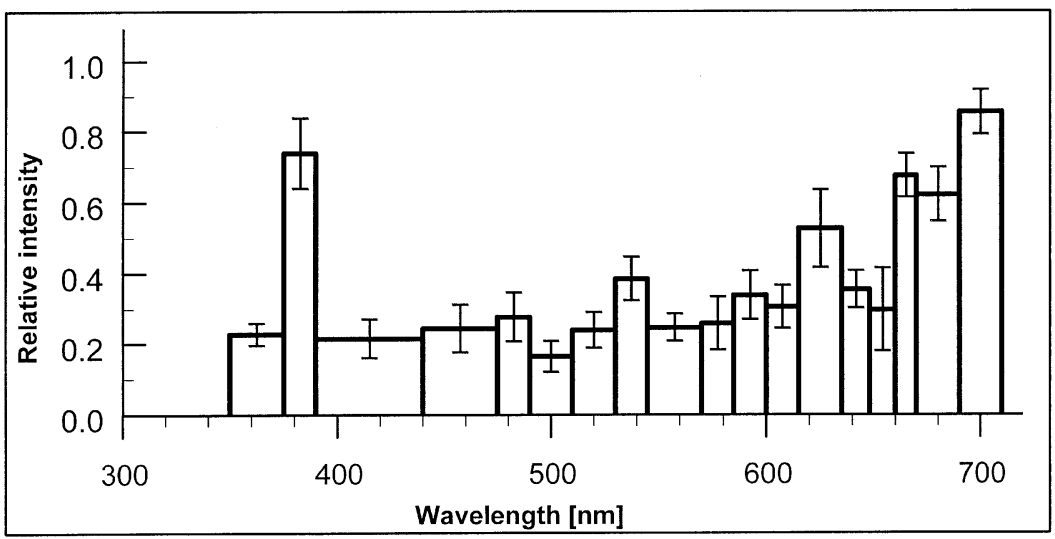

Fig. 4. Histogram of the spectral distribution of ultraweak luminescence from Characeae cells at the temperature of $20^{\circ} \mathrm{C}$. (the average of seven series; the vertical bars mean the standard errors).

There are basically two major emitters responsible for ultraweak luminescence from plants in the wavelength range recorded by our equipment. These are chlorophyll-a and excited molecules of oxygen $\mathrm{O}_{2}$ and carbonyl compounds.

Emission of chlorophyll measured from isolated chloroplasts ranges within the wavelength from $630 \mathrm{~nm}$ to over $800 \mathrm{~nm}$ while the spectral distribution depends on the time after illumination (Hideg, Kobayashi \& Inaba, 1992). The aforementioned emission is due to energy transfer of excited forms of singlet oxygen and carbonyl groups into particles of chlorophyll (Chen, Zhou, Li Xing, Van Wijk, \& Tang, 2006). Moreover, location of chloroplasts by cell wall fosters absorption of photons from the internal structures of cells and their reemission to the outside.

The second source of ultraweak luminescence, that is singlet oxygen molecules and carbonyl groups, emits photons during transition from excited to base states. Molecules of singlet oxygen $\left({ }^{1} \Sigma^{+}\right)$in the transition to the triplet state $\left({ }^{3} \Sigma_{\mathrm{g}}^{-}\right)$emit wavelengths of $762 \mathrm{~nm}$, while the dimoles of singlet oxygen respectively: $382 \mathrm{~nm}$ $\left(2\left[{ }^{1} \Sigma^{+}\right]\right), 580 \mathrm{~nm} 634 \mathrm{~nm}, 703 \mathrm{~nm},\left(2\left[{ }^{1} \Delta_{\mathrm{g}}\right]\right)$ and $478 \mathrm{~nm}$ $\left(\left[{ }^{1} \Sigma^{+}{ }_{\mathrm{g}}\right]\left[{ }^{1} \Delta_{\mathrm{g}}\right]\right)($ Cadenas \& Sies, 1984; Krasnovsky, 2008; Sławińska, 1990; Jaskowska, Borc, Milczarek, Dudziak \& Śpiewla, 2001). We were not able to record the radiation of singlet oxygen ${ }^{1} \Delta_{\mathrm{g}}$ with $1270 \mathrm{~nm}$ wavelength by means of our apparatus. Furthermore, excited triplet carbonyl compounds returning to the ground states emit photons in the wavelength range 350 - 480 nm (Havaux, Triantaphylides \& Genty, 2006).

The overall UWL levels of chlorophyll, oxygen molecules and carbonyl groups both in the visible and infrared ranges may depend on temperature in a similar way (irrespective of possible variations for each source of radiation). As a consequence, this may result in the constant ratio of their values regardless of temperature. This conclusion from our experimental observations requires further experimental confirmations.

An increase of UWL intensity observed in our temperature research is most probably associated with oxidative damage of unsaturated lipids by enzymatic and non-enzymatic reactions occurring in cells which are kept in dark (Boveris, Varsavsky, Da Silva \& Sanchez, 1983). Lipid peroxidation is an important radical process, which is also accountable for the singlet oxygen creation (Rice-Evans, Diplock \& Symons, 1991; Rao, Sriedevi \& Satyanarayana, 2002). Higher temperature induces an increase of lipid peroxidation in animal tissues (Parihar, Dubey, Javeri \& Prakash, 1996; Chien \& Hwang, 2001; Carvalho, Carvalho \& Bastos, 2001), as well as in plant cells (Rao et al., 2002; Ali, Hahn \& Paek, 2005; Liu, Guo, Pu, Feng, Zhu \& Peng, 2006). We suppose that together with intensification of lipid peroxidation the amount of both singlet oxygen and carbonyl groups increases. This causes the increase of UWL intensity because luminescence is one of the ways by which the excited molecules can return to the ground state - directly or by transferring energy to the 
chlorophyll (Slawinski \& Popp, 1987; Khan, 1989; Chen et al., 2006).

A process whose intensity in plants depends on the temperature is also respiration (Necchi, 2004, Vieira \& Necchi, 2006). Respiration processes lead to electron leakage in the respiratory chain and consequently to peroxidation of mitochondrial membrane lipids accompanied by spontaneous emission of photons (Hideg, Kobayashi \& Inaba, 1991). Thus, the increase of the UWL with temperature is partially caused by higher intensity of respiration.

An increase of UWL intensity in successive cycles of temperature one can be justified, as we suppose, by the rebuilding of lipid membrane induced by heat shock (Aid, Kesri-Benhassaine, Demandre \& Mazliak, 1998). However, the longer lasting heat shock consisting of temperature cyclic changes caused reduction of lipid peroxidation (Rao et al., 2002). Moreover, this effect may be related to the production of protective antioxidant enzymes acting protective role under high temperature stress. The occurrence of these enzymes was found in studies of cultivated plants subjected to high temperature (Almeselmani, Deshmukh, Saira, Kushwaha \& Singh, 2006). All this could be an explanation of UWL intensity decrease in the fourth and in further cycles of changes and of disappearance of hysteresis loop (Fig.3). At the same time it is an evidence that the cells are hardened.

As it was mentioned, the area between the curves of hysteresis loop in every cycle can determine the state of a homeostasis perturbation of the plant. The existence of this kind of changes indicates the inertia processes connected with temperature changes. The loop disappearance in the later cycles can suggest that there are the adaptation processes under way.

The phenomenon of hysteresis loop decay can testify that the range of applied temperatures for Characeae plants is such that autoregulation of cell processes takes place.

It should be emphasized that the processes associated with UWL emission and their temperature dependencies are very complicated and have not been explained entirely. With temperature variations the following parameters change: enzymatic activity, rotational diffusion coefficient of particular membrane compounds protein-lipid interaction, permeability and membrane fluidity. It leads to perturbation in transport of ions and other compounds. Phase transitions of membrane appear as well. Different sensibility of particular pathways and metabolic processes can lead to the deficit or to the excess of some metabolites. Response of cells on the appearance of heat shock is the generation of protective reactions and adaptation processes, among others: by heat shock proteins synthesis and the rebuilding of cell membrane (increase of saturated fatty acids participation) (Aid et al., 1998). This will eventually result in a complete adaptation to variable temperature conditions, i.e. thermotolerance, of course, if membranes do not earlier lose their functions or the cell does not begin to undergo destruction.

\section{CONCLUSIONS}

Answering the questions stated in the introduction we find that: 1) faster rate of temperature changes in the range of one cycle causes greater perturbation of homeostasis, which is illustrated by larger area of hysteresis loop outlined by $\mathrm{I}_{\mathrm{UWL}}=\mathrm{f}(\mathrm{T})$; 2) adaptation processes in the cells must exist because after a few hours, dependent on the way of temperature changes, the loops of temperature hysteresis disappear; 3) it follows from the spectral analysis that the main emitters of UWL do not change with a temperature increase, although radiation emission intensity significantly increases, a fact which is an evidence that the amount of generated excited states increases as well. From the obtained results we conclude that the methods of ultraweak luminescence measurements are useful in monitoring dynamic temperature changes in living organisms.

\section{REFERENCES}

Aid F., Kesri-Benhassaine G., Demandre C. \& Mazliak P. (1998). Modification of the biosynthesis of rape lipid molecular species by heat shock. Phytochemistry, 47, 11951200 .

Ali M. B., Hahn E. J. \& Paek K. Y. (2005) Effects of temperature on oxidative stress defense systems, lipid peroxidation and lipoxygenase activity in Phalaenopsis. Plant Physiol. Biochem., 43, 213-223.

Almeselmani M., Deshmukh P. S., Sairam R. K., Kushwaha S. R. \& Singh T. P. (2006). Protective role of antioxidant enzymes under high temperature stress. Plant Sci. 171, 382388.

Beljanski M. V., Andjus P. R., Hadzi-Pavlović A., Srejic R. A. \& Vucelić V. (1997). Differential scanning calorimetry of the plasma membrane-enriched fraction in Chara. Plant Sci., 125, 171-176.

Blatt F. J. (1974). Temperature dependence of the action potential in Nitella flexilis. Biochim. Biophys. Acta, 329, 382-389.

Boveris A., Varsavsky A. I., Da Silva S. G. \& Sanchez R. A. (1983). Chemiluminescence of soybean seeds: Spectral analysis, temperature dependence and effect of inhibitors. Photochem. Photobiol., 38, 99-104.

Cadenas E. \& Sies H. (1984). Low-level chemiluminescence as an indicator of singlet molecular oxygen in biological systems. Methods Enzymol., 105, 221-231.

Carvalho M., Carvalho F. \& Bastos M. L. (2001). Is hyperthermia the triggering factor for hepatotoxicity induced by 3,4-methylenedioxymethamphetamine (ecstasy)? An in vitro study using freshly isolated mouse hepatocytes. Arch. Toxicol., 74, 789-793. 
Chen W. L., Zhou Q., Li L., Xing D., Van Wijk R. \& Tang Y. H. (2006). Comparing ultraweak bio-chemiluminescence emission in wounded green and etiolated soybean cotyledons. Proc. SPIE, 6088, 60881G1-60881G10.

Chien L. T. \& Hwang D. F. (2001). Effects of thermal stress and vitamin $\mathrm{C}$ on lipid peroxidation and fatty acid composition in the liver of thornfish Terapon jarbua. Comp. Biochem. Phys. B, 128, 91-97.

Demidchik V. V., Naidun S. N., Yablontskaya L. I., Sokolik A. I. \& Yurin V. M. (2001). Alteration of ion channels in the plasmalemma of Nitella flexilis cells during long-term hyperthermia. Russ. J. Plant Physiol., 48, 294-299.

Devaraj B., Usa M. \& Inaba H. (1997). Biophotons: ultraweak light emission from living systems. Curr. Opin. Solid State Mat. Sci., 2, 188-193.

Djurisić M. R. \& Andjus P. R. (2000). Temperature sensitivity of the tonoplast $\mathrm{Ca}(2+)$-activated $\mathrm{K}+$ channel in Chara: the influence of reversing the sign of membrane potential. $J$. Membr. Biol., 178, 215-224.

Gabryś, H. (1979). The types of cytoplasmic motion in plant cells and mechanisms of its creating. Mater. Mol. Biol., 6, 99-109 (in polish)

Havaux M., Triantaphylides C. \& Genty B. (2006). Autoluminescence imaging: a non-invasive tool for mapping oxidative stress. TRENDS Plant Sci., 11, 480-484.

Hertel A. \& Steudle E. (1997). The function of water channels in Chara: The temperature dependence of water and solute flows provides evidence for composite membrane transport and for a slippage of small organic solutes across water channels. Planta, 202, 324-335.

Hideg E, Kobayashi M. \& Inaba H. (1991). Spontaneous ultraweak light emission from respiring spinach leaf mitochondria. Biochim. Biophys. Acta - Bioenergetics, 1098 27-31.

Hideg E, Kobayashi M. \& Inaba H. (1992). Delayed fluorescence and ultraweak light emission from isolated chloroplasts (comparison of emission spectra and concentration dependence). Plant Cell Physiol. 33, 689-693.

Inaba H. (1988). Super-high sensitivity systems for detection and analysis of ultraweak photon emission from biological cells and tissues. Experientia, 44, 550-559.

Jaśkowska A., Borc R., Dudziak A., Milczarek I. \& Śpiewla, E. (2001). Ultraweak biochemiluminescence of darkadapted Characeae cells. Curr. Top. Biophys., 25, 95-101.

Jaśkowska A., Borc R., Milczarek I., Dudziak A. \& Śpiewla E. (2001). Kinetics studies of ultraweak luminescence induced by ascorbic acid in Characeae cells and their structures. Luminescence, 16, 51-56.

Jaśkowska A., Górski Z., Dudziak A. (2003). Light emission from algae as a signaling of metabolic changes. Proc. SPIE, 5566, $15-22$.

Khan A. U. (1989). Near infrared emission of singlet oxygen generated in the dark. J. Biol. Chem., 4, 200-207.

Kobayashi M., Kibuchi D. \& Okamura H. (2009). Imaging of Ultraweak spontaneous proton emission from human body displaying diurnal rhythm. PLOS ONE, 4(7), e6256.

Korthout H., Berecki G., Bryin W., van Duijn B. \& Wang M. (2000). The presence and subcellular localization of caspase 3-like proteinases in plant cells. FEBS Lett., 475, 139-144.

Krauss W. Physiology and biochemistry of algae. (1962). Academic Press, New York.
Krasnovsky Jr. A. A. (2008) Luminescence and photochemical studies of singlet oxygen photonics. (2008). J. Photochem. Photobiol., 196, 210-218.

Liu P., Guo W. S., Pu H. C., Feng C. N.. Zhu X. K. \& Peng Y. $X$. (2006). Effects of high temperature on antioxidant enzymes and lipid peroxidation in flag leaves of wheat during grain filling period. Agric. Sci. China, 5, 425-430.

Makino T., Kato K., Iyozumi H. \& Aoshima Y. (2005). Biophoton emission and defense systems in plants. [In:] Shen X., Van Wijk R. (eds.) Biophotonics: Optical Science and Engineering for the 21st Century. New York, Verlag Springer Science, pp. 205-218.

Nakamura K. \& Hiramatsu M. (2005). Ultra-weak photon emission from human hand: Influence of temperature and oxygen concentration on emission. J. Photochem. Photobiol. B: Biology, 80, 156-160.

Necchi O. Jr. (2004). Photosynthetic responses to temperature in tropical lotic macroalgae. Phycol. Res., 52, 140-148.

Ogata K. (2000). The double-water-film electrode: A device for measuring the resistance and the capacitance of the internode/node interface of Chara as functions of time and temperature. J. Plant Growth Regul., 19, 98-105.

Parihar M. S., Dubey A. K., Javeri T. \& Prakash P. (1996). Changes in lipid peroxidation, superoxide dismutase activity, ascorbic acid and phospholipid content in liver of freshwater catfish heteropneustes fossilis exposed to elevated temperature. J. Therm. Biol., 21, 323-330.

Paszewski A. \& Śpiewla E. (1986). Temperature dependence of the membrane resistance in Characeae cells. Physiol. Plant., 66, 134-138.

Proseus T. E, Zhu G. L. \& Boyer J. S. (2000). Turgor, temperature and the growth of plant cells: using Chara corallina as a model system. J. Exp. Bot., 51, 1481-1494.

Radenovic C. N., Maksimov G. V., Jeremic M. G. \& Vuchinich Z. B. (2000). The study of microviscosity of plasma membranes of Nitella cells during rest and excitation. Biofizika, 45, 502-508.

Rao K. V. M., Sriedevi V. \& Satyanarayana N. V. (2002). Heat shock induced lipid changes and solute leakage in germinating seeds of pigeonpea. Biol. Plantarum, 45, 71-76.

Rice-Evans C. A., Diplock A. T. \& Symons M. R. C. (1991). Techniques in free radical research. [In:] Burdon R. H., van Knippenberg P. H. (eds.) Techniques in Biochemistry and Molecular Biology. Amsterdam, Elsevier, pp. 185-194.

Roschger P., Scott R. Q., Devaraj B. \& Inaba H. (1993). Observation of phase transitions in intact leaves by intrinsic low-level chemiluminescence. Photochem. Photobiol., 57, 580-283.

Sławinska D. (1990). Spectral analysis of ultraweak photon emission from plants. [In:] Jeżowska-Trzebiatowska B., Kochel B., Sławinski J., Strąk, W. (eds.) Biological luminescence., Singapore, World Scientific Publishing., pp. 197-213.

Slawinski J. \& Popp F. A. (1987). Temperature hysteresis of low-level luminescence from plants and its thermodynamical analysis. J. Plant Physiol., 130, 111-123.

Triglia A., Grasso F., Musumeci F., Scordino A., Luciani F., Battiato A., Allegra A. \& Rajfur Z. (1993). Temperature dependence of the ultraweak spontaneous photon emission from soya seeds. Nuovo Cimento D, 15, 1361-1370.

Tryka S. (1998). Cut-off filter method for light-induced photon emission spectra estimation. Comput. Chem., 22, 113-118. 
Uchida G., Nemoto T. \& Tsuchiya Y. (1995). Characteristics in sliding motion of small organelles in a Nitella internodal cell. J. Phys. Soc. Jpn., 64, 4959-4963.

Vieira J. Jr. \& Necchi O. Jr. (2006). Photosynthetic characteristics of a tropical population of Nitella cernua (Characeae, Chlorophyta). Braz. J. Plant Physiol., 18, 379388.
Wayne R., Staves M. P. \& Leopold A. C. (1990). Gravitydependent polarity of cytoplasmic streaming in Nitellopsis. Protoplasma, 155, 43-57.

Yan Y., Popp F. A., Sigrist S., Schlesinger D., Dolf A., Yan Z., Cohen S. \& Chotia A. (2005). Further analysis of delayed luminescence of plants. J. Photochem. Photobiol. B, 78, 235-244. 